\title{
The Role of Items Quantity Constraint to Control the Optimal Economic Order Quantity
}

\author{
Karzan Mahdi Ghafour ${ }^{1}$ \\ ${ }^{1}$ College of Administration and Economics, University of Sulaimani, Kurdistan-Iraq \\ Correspondence: Karzan Mahdi Ghafour, College of Administration and Economics, University of Sulaimani, \\ Kurdistan, Iraq. Tel: 964-770-149-3330. E-mail: Karzan.ghafour@gmail.com
}

Received: July 19, 2017

Accepted: July 30, 2017

Online Published: August 21, 2017

doi:10.5539/mas.v11n9p61

URL: https://doi.org/10.5539/mas.v11n9p61

\begin{abstract}
The obligation or the traditional question in inventory models is how much or how many of inventory items to order. In inventory control, the economic order quantity, EOQ is varies from model to another based on the variables and assumptions. This paper develops the EOQ using two deterministic inventory models (Purchases model and production model with shortage) of multi-items when the objective function is subjected to a constrained number of items quantities. The constraints are supposed to be active if the left-hand side does not satisfy the right-hand side condition. Thus, to achieve the new formula of multi-item EOQ in each of the two models with the constraint, Lagrange method have been used. Finally, to provide the proposed model a numerical example has been used.
\end{abstract}

Keywords: deterministic inventory models, economic order quantity and lagrange method

\section{Introduction}

The body Establish Nearly a century ago, Harris (1913) suggested the model of economic order quantity (EOQ). Five years later, Taft (1918) suggested the production quantity (EPQ) model. Later still, Hadley and Whitin (1963) suggested the EOQ/EPQ model. The inventory control policy attends to two conventional decisions: 'How much to order (produce or purchase) to replenish the inventory of an item' and 'When to order'. Numerous inventory models have been developed and modified to answer these two questions. The perfect order quantity is the primary assumption of the classical EOQ. However, the presence of a large number of elements that cannot be avoided, most of the proposed inventory models are developed and modified in the deterministic area (Khan, Jaber, Guiffrida, \& Zolfaghari, 2011; Pentico \& Drake, 2011; Yousefli \& Ghazanfari, 2012). The main idea of the EOQ is that stock-out is not allowed. In addition, the assumption of demand and the lead-time are fixed and known. The EOQ model points to the trade-off between ordering and storage cost in choosing the quantity to replenish items. A large EOQ will decrease ordering repetition; hence reducing the cost of the order per unit time. On the other hand, doing this increases depot holding cost. Conversely, small EOQ decreases the holding cost but increases the ordering frequency as well as cost per unit time. For many years, the classical EOQ problem was discussed in detail and resolved by many researchers (Frederick \& Gerald, 2001; Hamdy, 2007; Schwarz, 1972). Starting from a single-item model with associated demand to unit price through the development of a multi-item model with many constraints (Cheng,1989). These procedures are fully analytical and include complex calculations to get the optimal solution. A simple approach for determining production quantity of a product with imperfect quality was introduced by Goyal and Cárdenas-Barrón (2002). The approach aimed to obtain near-optimal results. Rezaei ( 2005), Papachristos and Konstantaras (2006), Wee et al. (2007) and Chang and Ho (2010) studied the problem by considering the incidence of shortage. Khan, Jaber and Bonney (2011) developed a mathematical model of inspection which consists of three costs: inspection cost, cost error.

De Schrijver, Aghezzaf, and Vanmaele (2013) considered independent multi-item inventory problems with aggregate constraints and included one of the following characteristics: constant lead-time demand, news-vendor, base stock policy, (r, Q) policy and (s, S) policy. They analyzed some modern related references and investigated different versions of the problem, resulting in suggested model formulations and the algorithmic approaches.

Pasandideh, Niaki and Mousavi (2013) presented a multi-item multi-period inventory control problem with all units and/or gradual quantity discount policies under restricted storage capacity. They assumed known independent random demand rates of the items in the periods with ordering, holding, and purchasing costs. They 
aimed to find the optimal EOQ of all items in various periods such that the total inventory cost being minimized and the constraint satisfied. Rezaei (2014) proposed a general mathematical model, which was used for various types of growing products, followed by a particular mathematical model for specific types of poultry. Kumar and Singh (2015) built an inventory model with two depots and a dependent demand rate in which demand rate was a polynomial of current inventory level. Furthermore, they assumed the value of system engaged in repetitive operations decreases.

This paper aims to develop a mathematical model for two deterministic inventory models (i.e. Purchases with Shortage and Production with Shortage) to establish a new formula of EOQ in a multi-item inventory when the objective function is subjected to a number-of-items quantity constraint. The achievement of this condition can be made when the left-hand side of the constraint does not satisfy the right-hand side, which means the constraint is active. In a previous work we developed a new formula of EOQ in multi-items for when the objective function is subjected to annual number of orders constraints ; we presented a numerical example to show the effect of the constraints on EOQ when it is active and the changes in the value of EOQ (Ghafour, Ramli, \& Zaibidi, 2015). Later in Ghafour and Rashid (2016), the formula of multi-items EOQ was developed when the objective function is subjected to a number-of-annual-order constraint and we presented a numerical example to show the effect. Thus, this paper is an extension of the aforesaid papers to establish a new formula of EOQ in the same deterministic inventory models (Purchases with Shortage and Production with Shortage) when the constraint of number of items quantity is active.

\section{Problem Description and Assumptions}

This paper examines and investigates two deterministic multi item inventory control models, which are intended, the classical economic order quantity, EOQ. Generally, deterministic inventory control models divided into four models with constant demand rate and fixed, constant or zero lead-time supposition (Buzacott, 1975; Chung and Liao, 2004; Ghare and Schrader, 1936; Ray and Chaudhuri, 1997; Schwarz, 2008, Schwarz 1972). However, this paper studies the deterministic multi-item inventory control models (purchase with shortage and production with shortage) to establish a new formula of EOQ subjected to number of items quantity. To classify these models, there are a few assumptions and notations as follows:

\section{- Assumption}

The following assumptions are made to develop the model

- The replacement is instantaneous for model 1.

- The replacement is gradual for model 2.

- The demand is fixed and known.

- Zero Lead-time.

- Allowed shortage in both models.

\section{- Notations}

$Q$ Economic order quantity/order.

$Z$ Total inventory cost

$K$ Setup cost/ per order

$h$ Holding cost/ per unit and time $=\mathrm{I}^{*} \mathrm{C}$

C Unit cost

I Inventory holding cost percentage (\%)

$p$ Cost of shortage per unit and unit time

$\beta$ Demand rate per unit and unit time

$\alpha$ Production rate per unit per unit time

$S$ Maximum shortage quantity.

\subsection{Model of Purchases with Shortage}

In this model, the situation of shortage is allowable. Practically, when the inventory cannot satisfy customer demand, the manufacturer or the concerned party must pay off the required quantities, which means access to the shortage, and this shortage leads to fines imposed for the failure to meet the needs of the customers. The shortage can be classified as loss profit or loss of the quantity in the depot. Therefore, this model aims to find the optimal 
EOQ and at the same time the maximum shortage quantity that can be expected and do so at the minimum expected total cost. Theoretically, the EOQ, maximum shortage quantity and the minimum total cost function equations for this model(Hamdy, 2007; Hillier \& Lieberman, 2010)are:

$$
\begin{gathered}
Q^{*}=\sqrt{\frac{2 K \beta(p+h)}{h p}} \\
S^{*}=\sqrt{\frac{2 K \beta h}{p(p+h)}} \\
Z=\frac{k \beta}{Q}+h \frac{(Q-S)^{2}}{2 Q}+p \frac{S^{2}}{2 Q} \text { or } Z=\sqrt{\frac{2 k \beta b p}{(p+h)}+c \beta}
\end{gathered}
$$

\subsection{Model of Production with Shortage}

As the previous model indicates, the situation of shortage is allowable in this model. Moreover, the replenishment is gradual. Therefore, the Equations of EOQ, maximum shortage quantity and total cost function for this model (Hamdy, 2007; Hillier \& Lieberman, 2010) are:

$$
\begin{gathered}
Q^{*}=\sqrt{\frac{2 K \beta(p+h)}{h b p}} \\
S^{*}=\sqrt{\frac{2 K \beta h b}{h(p+h)}} \\
Z=\frac{k \beta}{Q}+h \frac{(Q b-S)^{2}}{2 Q b}+p \frac{S^{2}}{2 Q b} \text { or } \\
Z=\sqrt{\frac{2 k \beta h b p}{(p+h)}}+c \beta
\end{gathered}
$$

Where, $b=\left(1-\frac{\beta}{\alpha}\right)$

\section{Methodology}

This paper examines multi-item (purchase with shortage and production with shortage) inventory control models with constant demand and zero lead-time suppositions. In the model description, the EOQ Equation exemplified for single-item, which means $j=1$ where, $j$ is the number of items. Nevertheless, when $(n>1)$, i.e. for more than one item (multi-item) with the existence of number of items quantity constraints. This led us to further notation.

$Q j=$ the EOQ for each item $\mathrm{j}, \mathrm{j}=1,2, \ldots, \mathrm{n}$

$Z j=$ the total cost for each item $\mathrm{j}, \mathrm{j}=1,2, \ldots, \mathrm{n}$

$b_{1}=$ maximum number of items

All other variables noted previously will change for the multi-item $(j, j=1,2, \ldots, n)$. In addition, the constraint of number of items quantity can be obtainable as follows: 


$$
\sum_{j=1}^{n} Q_{j} \leq b_{1}
$$

The constraint of number of items quantity in the considered multi-item inventory models accomplished when the left-hand side of Equation (7) does not satisfy the right-hand side, i.e. when it is greater than the right-hand side. Therefore, the constraint is active. Hence, there is a need to substitute the EOQ $(Q)$ in Equations (1) and (4) by $(Q j)$ for the multi-item case. In this case, we need to fine the new value of $(Q j)$ and this done by using the Lagrange method.

$$
L(x, \lambda)=f(x)-\lambda\left(g(x)-b_{i}\right)
$$

Where, $f(x)$ is the objective function (total cost function) for the two models as Equations (3) and (6) and $\left(g(x)-b_{i}\right)$ represents the constraint as in Equation (7).

\subsection{Model of Purchases with Shortage and the Constraint}

To build a new formula of multi-item EOQ when the constraint number of items quantity is active, we integrate Equations (3) and (7) in Equation (8) as follows:

$$
\begin{gathered}
L(Q, \lambda)=\frac{k_{j} \beta_{j}}{Q_{j}}+h_{j} \frac{\left(Q_{j}-S_{j}\right)^{2}}{2 Q_{j}}+P_{j} \frac{S_{j}^{2}}{2 Q_{j}}-\lambda_{j}\left(\sum_{j=1}^{n} Q_{j}-b_{1}\right) \\
\frac{\partial}{\partial Q}=\frac{-k_{j} \beta_{j}}{Q_{j}^{2}}+\frac{h_{j}}{2}\left(\frac{2 Q_{j}\left(Q_{j}-S_{j}\right)-\left(Q_{j}-S_{j}\right)^{2}}{Q_{j}^{2}}\right)-P_{j} \frac{S_{j}^{2}}{2 Q_{j}}-\lambda_{j}=0
\end{gathered}
$$

Multiply Equation (10) by $Q_{j}^{2}$, we obtain,

$$
\begin{gathered}
-k_{j} \beta_{j}+\frac{h_{j}}{2}\left(2 Q_{j}-S_{j}\right) Q_{j}-\left(Q_{j}-S_{j}\right)^{2}-P_{j} \frac{S^{2}}{2}-\lambda Q_{j}^{2} \\
-k_{j} \beta_{j}+\frac{h_{j}}{2}\left(2 Q_{j}-2 Q_{j} S_{j}-Q_{j}^{2}+2 Q_{j} S_{j}-S_{j}\right)^{2}-\frac{P_{j} S_{j}^{2}}{2}-\lambda_{j} Q_{j}^{2}=0 \\
-k_{j} \beta_{j}+\frac{h_{j}}{2}\left(Q_{j}^{2}-S_{j}^{2}\right)-\frac{P_{j} S_{j}^{2}}{2}-\lambda_{j} Q_{j}^{2}=0
\end{gathered}
$$

Multiply Equation (11) by 2, we obtain,

$$
\begin{gathered}
h_{j} Q_{j}^{2}-h_{j} S^{2}-2 \lambda_{j} Q_{j}^{2}=2 k_{j} \beta_{j}+P_{j} S_{j}^{2} \\
\therefore Q_{j}=\sqrt{\frac{2 k_{j} \beta_{j}+P_{j} S_{j}^{2}+h_{j} S_{j}^{2}}{h_{j}-2 \lambda_{j}}}
\end{gathered}
$$

Equation (12) shows the new formula of multi-item EOQ in the inventory model of purchase with shortage when the constraint of number of items quantity is active. However, the problem in Equation (12) is the value of Lambda, $\lambda$, which is unknown. There are two ways to find the value of Lambda. The first way is by using the trial and error compensation method by giving a value to $\lambda$ starting with zero until it achieves the constraint condition or becomes as close as possible, whether positive or negative. The second way is by using the scientific method, which is more accurate by considering the derivation method from Equation (7) as follows:

$$
\sum_{j=1}^{n} \sqrt{\frac{2 k_{j} \beta_{j}+P_{j} S_{j}^{2}+h_{j} S_{j}^{2}}{h_{j}-2 \lambda_{j}}}=b_{1}
$$

where, $h_{j}=I_{j} * C_{j}$ 


$$
\begin{aligned}
& \sum_{j=1}^{n} \sqrt{\frac{2 k_{j} \beta_{j}+P_{j} S_{j}^{2}+I_{j} C_{j} S_{j}^{2}}{I_{j} C_{j}-2 \lambda_{j}}}=b_{1} \Rightarrow \\
& \sqrt{2 \lambda_{j}}=\frac{1}{b_{1}} \sqrt{2 k_{j} \beta_{j}+P_{j} S_{j}^{2}+C_{j} S_{j}^{2}} \\
& \lambda_{j}=-\frac{\left(\frac{1}{b_{1}^{2}} \sqrt{2 k_{j} \beta_{j}+P_{j} S_{j}^{2}+C_{j} S_{j}^{2}}\right)^{2}}{2}
\end{aligned}
$$

\subsection{Model of Production with Shortage and the Constraint}

To build a new formula of multi-item EOQ when the constraint of number of items quantity is active, by using the similar approach as in previous section, we integrate Equations (6) and (7) in Equation (8) as follows:

$$
\begin{gathered}
L(Q, \lambda)=\frac{k_{j} \beta_{j}}{Q_{j}}+h_{j} \frac{\left(Q_{j} b_{j}-S_{j}\right)^{2}}{2 Q_{j} b_{j}}+P_{j} \frac{S_{j}^{2}}{2 Q_{j} b_{j}}-\lambda\left(\sum_{j=1}^{n} Q_{j}-b_{1}\right) \\
\frac{\partial L}{\partial Q}=\frac{-k_{j} \beta_{j}}{Q_{j}^{2}}+\frac{h_{j}}{2 b_{j}}\left(\frac{2 Q_{j} b_{j}\left(Q_{j} b_{j}-S_{j}\right)-\left(Q_{j} b_{j}-S_{j}\right)^{2}}{Q_{j}^{2}}\right)+P_{j} \frac{S_{j}^{2}}{2 Q_{j} b_{j}}-\lambda_{j}=0 \\
\frac{\partial}{\partial \lambda}=b_{1}-Q_{j}=0 \\
-k_{j} \beta_{j} b_{j}+\frac{h_{j}}{2 b_{j}}\left(2 Q_{j} b_{j}^{2}-S_{j}\right) Q_{j}-\left(Q_{j}-S_{j}\right)^{2}+P_{j} \frac{S_{j}^{2}}{2}-\lambda_{j}
\end{gathered}
$$

Multiply Equation (16) by $Q_{j}^{2} b_{j}$, we obtain,

$$
\begin{gathered}
-k_{j} \beta_{j}+\frac{h_{j}}{2 b_{j}}\left(2 Q_{j}^{2} b_{j}^{2}-2 Q_{j} b_{j} S_{j}-2 Q_{j} b_{j} S_{j}-Q_{j}^{2} b_{j}^{2}+2 Q_{j} b_{j} S_{j}-S_{j}^{2}\right)+\frac{P_{j} S_{j}^{2}}{2 Q_{j}^{2} b_{j}}-\lambda_{j} Q_{j}^{2} b_{j}=0 \\
-k_{j} \beta_{j}+\frac{h_{j}}{2}\left(Q_{j}^{2} b_{j}^{2}-S_{j}^{2}\right)-\frac{P_{j} S_{j}^{2}}{2}-\lambda_{j} Q_{j}^{2} b_{j}=0, \\
h_{j} Q_{j}^{2} b_{j}^{2}-h_{j} S_{j}^{2}-2 \lambda_{j} Q_{j}^{2} b_{j}=2 k_{j} \beta_{j} b_{j}+P_{j} S_{j}^{2} \\
\therefore Q_{j}=\sqrt{\frac{2 k_{j} \beta_{j} b_{j}+P_{j} S_{j}^{2}+h_{j} S_{j}^{2}}{h_{j} b_{j}-2 \lambda_{j} b_{j}}}
\end{gathered}
$$

Equation (17) shows the new formula of multi-item EOQ in the inventory model of production with shortage when the constraint of number of items quantity is active. The same problem appears as Equation (12), which is the value of Lambda. However, by the similar approach as Equation (14) we can extract the value of Lambda, $\lambda$.

$$
\sum_{j=1}^{n} \sqrt{\frac{2 k_{j} \beta_{j} b_{j}+P_{j} S_{j}^{2}+h_{j} S_{j}^{2}}{h_{j} b_{j}-2 \lambda_{j} b_{j}}}=b_{1}
$$

where, $h_{j}=I_{j} * C_{j}$

$$
\begin{gathered}
\sum_{j=1}^{n} \sqrt{\frac{2 k_{j} \beta_{j} b_{j}+P_{j} S_{j}^{2}+I_{j} C_{j} S_{j}^{2}}{I_{j} C_{j} b_{j}-2 \lambda_{j} b_{j}}}=b_{1} \Rightarrow \\
\sqrt{b_{j}-2 \lambda_{j}}=\frac{1}{b_{1}} \sqrt{2 k_{j} \beta_{j}+P_{j} S^{2}+S^{2}}
\end{gathered}
$$




$$
\lambda_{j}=-\frac{\left(\frac{1}{b_{1}^{2}} \sqrt{2 k_{j} \beta_{j}+P_{j} S^{2}+S^{2}}\right)^{2}}{2}
$$

\section{Numerical Example}

After Example: To clarify the result of the theory described above, the example of (Ghafour \& Rashid, 2016) are used. The parameters illustrate the concept of the first model with total number of items quantity. However, Table 1 represents all the parameters of the model with the total allowed number of items quantity being equal to 7.

Table 1. Given parameters of the three items with total allowed number of items is equal to 104

\begin{tabular}{lllllll}
\hline Items & $\beta_{j}$ & $K_{j}(\$)$ & $h_{j}(\$)$ & $C_{j}(\$)$ & $P_{j}(\$)$ & $S_{j}$ \\
\hline 1 & 33 & 25 & 1 & 1 & 3 & 14 \\
2 & 24 & 18 & 1.5 & 0.5 & 6 & 13 \\
3 & 20 & 20 & 2 & 2.5 & 8 & 12 \\
\hline
\end{tabular}

At the first, we find the $Q_{j}$ for the three items by applying Equation (12) assuming $\lambda=0$ to show the constraint is active or not. Thus, $Q_{1}=49.34 /$ week, $Q_{2}=37.70 /$ week and $Q_{3}=33.47 /$ week. Thus, $\sum_{j=1}^{3} Q_{j} \leq b_{1} \Rightarrow 120.5 \leq 104$. When the constraint does not satisfy the condition, this means the constraint is active. Therefore, we should find the new $Q_{j}$ for each item with the new value of Lambda. See Table 2 for results.

Table 2. Results of the new $Q_{j}$ and the values of $\lambda_{j}$ based on Equation (14)

\begin{tabular}{ccc}
\hline Items & $\lambda_{j}$ & $Q_{j}$ \\
\hline 1 & -0.231 & 40.80 \\
\hline 2 & -0.231 & 32.96 \\
\hline 3 & -0.231 & 30.16
\end{tabular}$\sum_{i=1}^{3} Q_{j}=103.93 \leq b_{1}=104$

Based on the allowable total number of items quantity, the values of the EOQ decreased for each item. These new values of EOQ are optimal when $\lambda=-0.231$, which means optimal exploitation of the number of items quantity was achieved.

\section{Discussion}

The numerical example shows the importance of the items quantity constraint to control the economic order quantity, EOQ. This constraint has a role to find the new optimal EOQ based on the new value of Lambda, $\lambda$. This optimal EOQ avoid the manufacturer to falling into overstock or understock. Overstock or understock leads to more costs or shortage then loss profits. However, this developed model can be applied on more real situations, for example (Kanban and Heijunka) model or any situations need storage more than one items.

\section{Conclusion}

The models of purchase with shortage and production with shortage were developed and analyzed when subjected to number of items quantity. The numeric advantage of using these equations are very important and necessary when we cannot exceed the total number of items quantity, and thus must establish these new equations of the EOQ for optimum exploitation of the number of items quantity that also do not exceed the constraint. The results show the constraint with each inventory model that we presented can help the decision maker to find the optimal EOQ for each item in each model by using the Lagrange method, thus determining the optimal quantity of shortage and the minimum total cost. The new EOQ can be used and applied in many real circumstances such as general warehouses, storage in supermarkets, production storage which stores more than one item and need more space and specific decisions about the EOQ

\section{References}

Buzacott, J. A. (1975). Economic order quantities with inflation. Operational research quarterly. Operations 
Research Quarterly, 26, 553-558. https://doi.org/10.1057/jors.1975.113

Chang, H.-C., \& Ho, C. H. (2010). Exact closed-form solutions for "optimal inventory model for items with imperfect quality and shortage backordering." Omega, 38(3), 233-237. JOUR. https://doi.org/http://dx.doi.org/10.1016/j.omega.2009.09.006

Chung, K. J., \& Liao, J. J. (2004). Lot-sizing decisions under trade credit depending on the ordering quantity. Computers \& Operations Research, 31(6), 909-928. https://doi.org/10.1016/S0305-0548(03)00043-1

De Schrijver, S. K., Aghezzaf, E. H., \& Vanmaele, H. (2013). Aggregate constrained inventory systems with independent multi-product demand: Control practices and theoretical limitations. International Journal of Production Economics, 143(2), 416-423. https://doi.org/10.1016/j.ijpe.2011.08.019

Frederick, S. H., \& Gerald, J. L. (2001). Introduction to Operations Research (seven edit). McGraw-Hill, New York.

Ghafour, K. M., \& Rashid, R. H. (2016a). Optimizing Multi-Item EOQ when the Constraint of Annual Number of Orders is Active. Modern Applied Science, 11(1), 55. https://doi.org/10.5539/mas.v11n1p55

Ghafour, K. M., \& Rashid, R. H. (2016b). Optimizing Multi-Item EOQ when the Constraint of Annual Number of Orders is Active. Modern Applied Science, 11(1), 55. https://doi.org/10.5539/mas.v11n1p55

Ghafour, K., Ramli, R., \& Zaibidi, N. Z. (2015). Development of multi-item EOQ when the constraints of investment and storage capacity are active. In AIP (Vol. 30005, p. 30005). https://dx.doi.org/10.1063/1.4937024

Ghare, P. M., \& Schrader, G. F. (1936). A model for exponentially decaying inventory. Journal of Industrial Engineering, 14(5), 238-243.

Goyal, S. K., \& Cárdenas-Barrón, L. E. (2002). Note on: economic production quantity model for items with imperfect quality-a practical approach. International Journal of Production Economics, 77(1), 85-87. JOUR. https://dx.doi.org/10.1016/S0925-5273(01)00203-1

Hadley, G., \& Whitin, T. M. (1963). Analysis of inventory systems. (E. Cliffs, Ed.). Prentice Hall, New Jersey.

Hamdy, A. T. (2007). Operations Research an introduction. (H. Stark, Ed.) (7th editio). Pearson Prentic Hall.

Harris, F. W. (1913). How many parts to make at once. Magazine of Management, 10, 135-136. JOUR. https://dx.doi.org/10.1287/opre.38.6.947

Hillier, F. S., \& Lieberman, G. J. (2010). Introduction to operations research (pp. 195-259). Dubuque, IA: McGraw-Hill (Dubuque, I). JOUR, Dubuque, IA: McGraw-Hill, New York.

Khan, M., Jaber, M. Y., \& Bonney, M. (2011). An economic order quantity (EOQ) for items with imperfect quality and inspection errors. International Journal of Production Economics, 133(1), 113-118. https://doi.org/10.1016/j.ijpe.2010.01.023

Khan, M., Jaber, M. Y., Guiffrida, A. L., \& Zolfaghari, S. (2011). A review of the extensions of a modified EOQ model for imperfect quality items. International Journal of Production Economics, 132(1), 1-12. JOUR. https://doi.org/10.1016/j.ijpe.2011.03.009

Kumar, N., \& Singh, S. R. (2015). Effect of salvage value on a two-warehouse inventory model for deteriorating items with stock-dependent demand rate and partial backlogging. International Journal of Operational Research, 19(4), 479-496. https://doi.org/10.5267/j.uscm.2015.11.002

Papachristos, S., \& Konstantaras, I. (2006). Economic ordering quantity models for items with imperfect quality. International Journal of Production Economics, 100(1), 148-154. JOUR. https://doi.org/10.1016/j.ijpe.2004.11.004

Pasandideh, S. H. R., Niaki, S. T. A., \& Mousavi, S. M. (2013). Two metaheuristics to solve a multi-item multiperiod inventory control problem under storage constraint and discounts. International Journal of Advanced Manufacturing Technology (Vol. 69). https://doi.org/10.1007/s00170-013-5130-7

Pentico, D. W., \& Drake, M. J. (2011). A survey of deterministic models for the EOQ and EPQ with partial backordering. European Journal of Operational Research, 214(2), 179-198. https://doi.org/10.1016/j.ejor.2011.01.048

Ray, J., \& Chaudhuri, K. S. (1997). An EOQ model with stock-dependent demand, shortage, inflation and time discounting. International Journal of Production Economics, 53(2), 171-180. https://doi.org/10.1016/S0925-5273(97)00112-6 
Rezaei, J. (2005). Economic order quantity model with backorder for imperfect quality items. In Proceedings of IEEE International Engineering Management Conference (pp. 466-470). CONF.

Rezaei, J. (2014). Economic order quantity for growing items. International Journal of Production Economics, 155, 109-113. https://doi.org/10.1016/j.ijpe.2013.11.026

Schwarz, L. (2008). The Economic Order-Quantity (EOQ) Model. In D. Chhajed \& T. Lowe (Eds.), Building Intuition SE - 8 (Vol. 115, pp. 135-154). CHAP, Springer US. https://doi.org/10.1007/978-0-387-73699-0_8

Schwarz, L. B. (1972). Economic Order Quantities for Products with Finite Demand Horizons. A I I E Transactions, 4(3), 234-237. https://doi.org/10.1080/05695557208974855

Taft, E. W. (1918). The most economical production lot. Iron Age, 101(18), 1410-1412. JOUR.

Wee, H. M., Yu, J., \& Chen, M. C. (2007). Optimal inventory model for items with imperfect quality and shortage backordering. Omega, 35(1), 7-11. https://doi.org/10.1016/j.omega.2005.01.019

Yousefli, A., \& Ghazanfari, M. (2012). A Stochastic Decision Support System for Economic Order Quantity Problem. Advances in Fuzzy Systems, 2012, 1-8. https://doi.org/10.1155/2012/650419

\section{Copyrights}

Copyright for this article is retained by the author(s), with first publication rights granted to the journal.

This is an open-access article distributed under the terms and conditions of the Creative Commons Attribution license (http://creativecommons.org/licenses/by/4.0/). 